\title{
An Efficient Photocatalytic Degradation of Methyl Blue Dye by Using Synthesised PbO Nanoparticles
}

\author{
ASHOK V. BORHADE*, DIPAK R. TOPE and BHAGWAT K. UPHADE \\ Chemistry Research Center, \\ HPT Arts and RYK Science College, Nasik 422005, India \\ ashokborhade2007@yahoo.co.in
}

Received 31 August 2011; Accepted 8 November 2011

\begin{abstract}
We report here the synthesis of visible light sensitive $\mathrm{PbO}$ and $\mathrm{Ni}$ doped $\mathrm{PbO}$ nanoparticles by hydrothermal method and characterized by UVDRS, photoluminescence spectroscopy (PL), FTIR, X-ray diffraction (XRD), SEM, EDAX and TGA. Further an efficient approach has been developed for degradation of methyl blue (MB) in aqueous medium. The photodegradation of dye was monitored as a function of dye concentration, $\mathrm{pH}$ and catalyst amount has been determined. The reduction in the chemical oxygen demand (COD) revealed the mineralization of dye along with colour removal.
\end{abstract}

Keywords: Hydrothermal method, PbO nanoparticles, Photocatalyst, Visible light, Methyl blue dye.

\section{Introduction}

To develop more efficient photocatalyst, there is an urgent need for photocatalytic systems, which are able to operate effectively under visible light irradiation. The use of naturally available visible light has recently drawn much attention. Removal of organic dyes by photocatalytic degradation is emerging as an effective treatment method. Nowadays, photocatalyst is becoming more popular in water purification. The discharge of large quantity of coloured water from industries possess serious environmental problems. The colorization of water due to the presence of dyes may have an inhibitory effect on the process of photosynthesis and thus may affect the aquatic ecosystem. The coloured molecules absorbs visible light, decreasing the amount of light available for photosynthesis.

There are many methods for eliminating water pollutants. Widely used semiconductor photocatalysts like $\mathrm{ZnO}$ and $\mathrm{TiO}_{2}$ shows very low photoactivity under visible light excitation. Photocatalytic degradation of azo dye readily in water using $\mathrm{ZnO}^{1}$, the photocatalytic degradation of acid red $\mathrm{B}$ dye using $\mathrm{TiO}_{2}{ }^{2}$ was studied earlier. The photocatalytic degradation of methyl orange by zinc ferrite doped titania has also been reported $^{3}$. Use of semiconducting iron (II) oxide in photocatalytic bleaching of some dye has been reported by Ameta $^{4}$. A number of systems have been reported, they include transition metal doped $\mathrm{TiO}_{2}{ }^{5}$ nitrogen doped $\mathrm{TiO}_{2}{ }^{6}$ and photosensitization of dye pollutants ${ }^{7,8}$. Thus, the removal of dyes from coloured effluents is one of the major 
environmental problem. Many industries discharge untreated waste water on land causing pollution to surface water, ground water and soil ${ }^{9,10}$. The dye like rhodamine $\mathrm{B}^{11}$, reactive red- $2^{12}$ and malachite green ${ }^{13}$ was removed by activated carbon. The herbicide (thiram) was photocatalytically degraded by using $\mathrm{TiO}_{2}$ in presence of visible light $^{14}$. The $\mathrm{PbO}$ nanoparticles also used in sensor ${ }^{15}, \mathrm{Li}$ - ion batteries ${ }^{16}$, Lead -acid batteries ${ }^{17}$ and biomedical application ${ }^{18}$. Due to high concentration of organics in the effluents and the higher stability of modern synthetic dyes, the conventional biological treatment methods are ineffective for the complete colour removal and degradation of organics and dyes ${ }^{19}$.

Transition metal oxides with nanostructure have attracted considerable interest in many areas of chemistry, physics and material science. So, attempt was made to prepare materials that have absorption's extending towards visible range and thereby allowing the use of the main part of solar spectrum. The PbO nanoparticle was synthesized by different methods ${ }^{20-25}$. In the present study $\mathrm{PbO}$ and $\mathrm{Ni}$ doped $\mathrm{PbO}$ assisted photocatalytic degradation of methyl blue is reported.

\section{Experimental}

A mixture of $2.5 \mathrm{mmol}$ of citric acid and $0.1 \mathrm{~N}$ sodium hydroxide $(10 \mathrm{~mL})$ and a little water is added to a magnetically stirred methanolic solution of $2 \mathrm{mmol}$ lead nitrate at room temperature over $20 \mathrm{~min}$. The reaction mixture was stirred for $2 \mathrm{~h}$ at room temperature. The white solid product was filtered by vacuum, washed with distilled water and dried in an oven at $110{ }^{\circ} \mathrm{C}$ for $2 \mathrm{~h}$. The solid product was calcined at $500{ }^{\circ} \mathrm{C}$ for $2 \mathrm{~h}$.

\section{Synthesis of $3 \%$ and $7 \%$ Ni doped PbO nanoparticles}

$1 \mathrm{gm} \mathrm{PbO}$ nanoparticles were added to an aqueous solution of sodium hydroxide $(1 \mathrm{~N}, 10 \mathrm{~mL})$ in a Teflon autoclave. After vigorous shaking for several minutes nickel sulphate solution $(3 \%$ or $7 \%)$ was added to the reaction mixture. It was then stirred for another fifteen minutes. The reaction mixture was heated in an oven at $120{ }^{\circ} \mathrm{C}$ for $6 \mathrm{~h}$. The solid product was vaccum filtered off, washed with hydrochloric acid $(0.1 \mathrm{~N})$ and dried in an oven at $110{ }^{\circ} \mathrm{C}$ for $2 \mathrm{~h}$.

\section{Characterization}

The samples prepared by the hydrothermal method were characterized by FTIR (Schimadzu 8400S model). FTIR was used to observe the stretching of metal oxygen bond. UV-DRS spectra were recorded by using a Schimadzu UV 2450 spectrophotometer at room temperature. Photoluminescence (PL) spectrum at room temperature was recorded by Perkins Elmer spectrophotometer by using xenon arc lamp as the light source. The thermal stability was carried out using Perkins Elmer Thermal Analyzer up to $1000{ }^{0} \mathrm{C}$ in air at the heating rate of $20{ }^{0} \mathrm{C} / \mathrm{min}$. $\mathrm{PbO}$ nanoparticles calcined at $500{ }^{0} \mathrm{C}$ was employed for the powder XRD studies using Philips - 1710 diffractometer with $\mathrm{Cu}$ $\mathrm{K} \alpha$ radiation $\lambda=1.54 \mathrm{~A}^{0}$. A scanning electron microscope (SEM) with EDAX recorded by using JEOL JEM - 6360 was used to study the surface morphology of the lead oxide powder. The interaction of the nickel dopant with the host $\mathrm{PbO}$ semiconducting material by electron spins resonance (ESR) spectroscopy. The ESR spectrum was recorded by E-112 EPR spectrometer Varian, USA. 


\section{Photocatalytic degradation}

In photocatalytic degradation, methyl blue dye $(50 \mathrm{~mL})$ and the catalyst $(\mathrm{PbO}$ or $\mathrm{Ni}$ doped $\mathrm{PbO}$ photocatalyst) were taken in a beaker and exposed to sunlight. The dye solutions were mixed properly with a magnetic stirrer during the reaction process. Dye solutions of about 2-3 $\mathrm{mL}$ were taken out at regular interval and their absorbance was recorded at $610 \mathrm{~nm}$ using spectrophotometer (UV- Vis Ultra Spec CL - 540). The control experiments were also conducted under visible light without catalyst to measure any possible direct photocatalysis of this dye. Photocatalytic degradation of methyl blue was evaluated at different $\mathrm{pH}$, with various amounts of dye and various amounts of $\mathrm{PbO}$ photocatalysts, while all the reactions were carried out at $25^{\circ} \mathrm{C}$.

\section{Results and Discussion}

\section{Synthesis and characterization of $\mathrm{PbO}$ nanoparticles}

The FTIR spectra of $\mathrm{PbO}, 3 \%$ and $7 \% \mathrm{Ni}$ doped $\mathrm{PbO}$ nanoparticles are shown in Figure 1. The FTIR spectrum of $\mathrm{PbO}$ shows a broad band with very low intensity at $3446 \mathrm{~cm}^{-1}$ corresponding to the vibration mode of $\mathrm{OH}$ group indicating the presence of small amount of water adsorbed on the $\mathrm{PbO}$ nanoparticle surface. The band at $1408.08 \mathrm{~cm}^{-1}$ is due to $\mathrm{OH}$ bending of water. Bands at 574, 682 and $844 \mathrm{~cm}^{-1}$ are attributed to the $\mathrm{Pb}-\mathrm{O}$ vibrations. A new band at $920 \mathrm{~cm}^{-1}$ and $1047 \mathrm{~cm}^{-1}$ appeared in the $3 \% \mathrm{Ni}$ doped $\mathrm{PbO}$ nanoparticle due to presence of nickel ion. The 7\% Ni doped PbO nanoparticle shows a new strong band around 808 and $908 \mathrm{~cm}^{-1}$. The diffused reflectance spectra (Figure 2) shows band at $396 \mathrm{~nm}$ corresponds to $\mathrm{PbO}$ nanoparticle. Compared with bulk $\mathrm{PbO}$, the blue shift observed in the $\mathrm{PbO}$ nanoparticle is due to the size effect. The band gap energy for $\mathrm{PbO}$ nanoparticle is calculated from $\mathrm{E}=\mathrm{h} \nu=\mathrm{hc} / \lambda$. The band gap energy of $\mathrm{PbO}$ nanoparticles is $3.13 \mathrm{eV}$. In 3\% Ni doped $\mathrm{PbO}$ nanoparticle band shift from $396 \mathrm{~nm}$ to $402 \mathrm{~nm}$ and band gap energy has $3.08 \mathrm{eV}$. While in $7 \% \mathrm{Ni}$ doped $\mathrm{PbO}$ nanoparticle band shift from $396 \mathrm{~nm}$ to $407 \mathrm{~nm}$ and band gap energy is found to be $3.04 \mathrm{eV}$. The band position shows that absorption extending towards visible range (Figure 2).

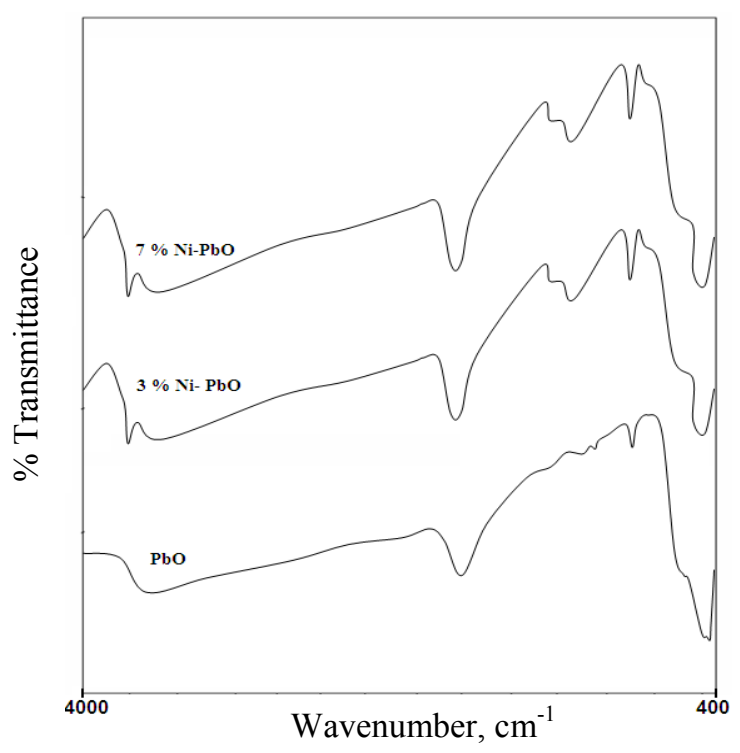

Figure 1. IR spectra of $\mathrm{PbO}$ and $\mathrm{Ni}$ doped $\mathrm{PbO}$ nanoparticles. 


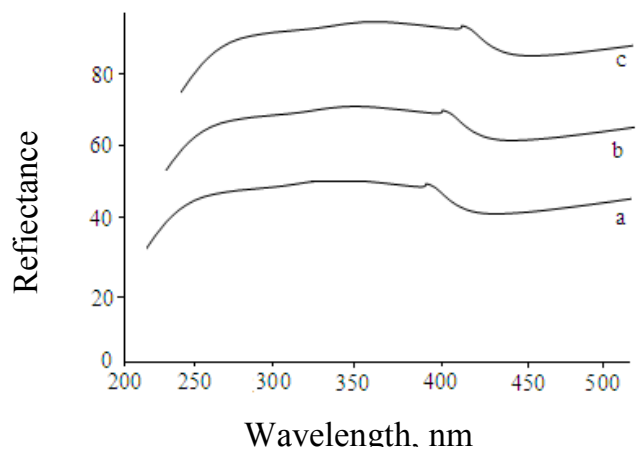

Figure 2. UV- DRS spectra of a) $\mathrm{PbO}$ nanoparticle, b) $3 \% \mathrm{Ni}$ doped $\mathrm{PbO}$ nanoparticle, c) $7 \% \mathrm{Ni}$ doped $\mathrm{PbO}$ nanoparticle.

Figure 3 depicts the photoluminescence spectrum (PL) of nano-size $\mathrm{PbO}$ particles synthesized in water, sodium hydroxide and citric acid shows a weak band at $370 \mathrm{~nm}$, a broad blue emission band at $473 \mathrm{~nm}$ and a strong green - yellow emission band at around $500 \mathrm{~nm}$. The ultraviolet band is attributed to the band - edge excitation recombination and the visible band is related to the defects in $\mathrm{PbO}$ nanostructures. The origin of blue emission from the undoped $\mathrm{PbO}$ is associated with the intrinsic defect centers such as oxygen vacancy, lead vacancy or oxygen interstitial. The observation of strong $473 \mathrm{~nm}$ blue band emission indicates the existence of oxygen vacancy concentrated on $\mathrm{PbO}$ nanoparticle surface. A strong band around $500 \mathrm{~nm}$ may be due to oxygen defects and gives green yellow emission. This green - yellow emission is observed in PL spectra due to recombination of photogenerated holes with singly ionized charge state of specific defect ${ }^{26}$.

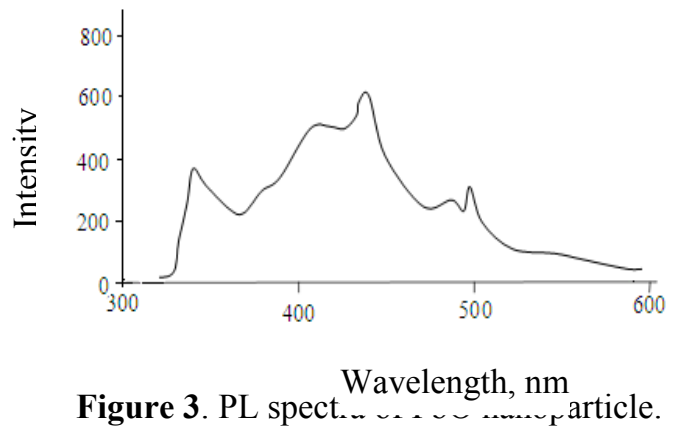

Figure 4 represents the typical XRD pattern of $\mathrm{PbO}$ nanoparticle. It shows peaks at an angle $29.1,30.4,32.5,37.7,49.4,50.9,53.3,56.2$ and 63.7 corresponds to the reflection from 111, 002, 200, 210, 022, 220, 222, 311 and 131 crystal planes respectively. The XRD pattern is an agreement with the orthorhombic structure of PbO (JCPDS Card No. 76 - 1796) with a space group Pca 2 (29). Sharp diffraction peak indicates good crystalinity of PbO nanoparticles. The broadening of peaks indicates that the particles are of nanometer scale which is in good agreement with observed SEM images. The XRD patterns of 3\% Ni doped $\mathrm{PbO}$ nanoparticles shows new peaks at 26.5, 31.8 and 48.6. The XRD pattern of $7 \% \mathrm{Ni}$ doped $\mathrm{PbO}$ nanoparticle shows new peaks at 18.6, 31.9 and 48.6. The change in diffraction patterns is due to encapsulation of nickel ion in $\mathrm{PbO}$ nanoparticle (Figure 4). The particle size was calculated using Scherrer formula. 


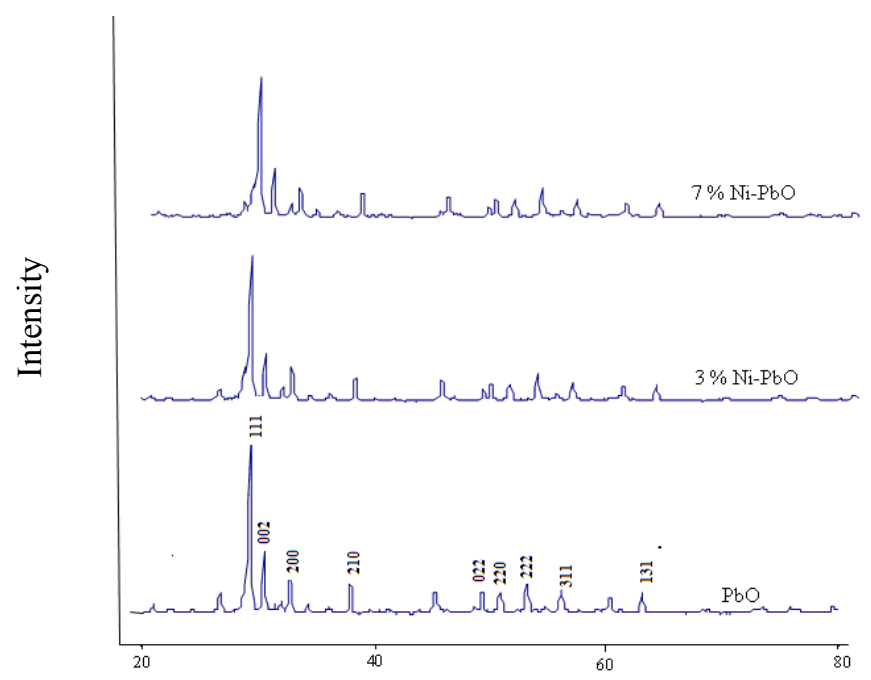

Figure 4. XRD pattern of $\mathrm{PbO}, 3 \% \mathrm{al}^{2 \theta} 7 \% \mathrm{Ni}$ doped $\mathrm{PbO}$ nanoparticles.

The average particle size can be estimated from the extrapolation of the plot (Figure 5) and the crystal size $(\varepsilon)$ was obtained $69 \mathrm{~nm}$ based on the intercept inverse, i.e., $1 / \varepsilon=0.144 \times 10,{ }^{8}$ which yields $\varepsilon=69 \mathrm{~nm}$. The average particle size of $3 \% \mathrm{Ni}$ and $7 \% \mathrm{Ni}$ doped $\mathrm{PbO}$ nanoparticles was found to be 64 and $61 \mathrm{~nm}$ respectively. As the doping level increases, the particle size decreases slightly. This may be due to the fact that dopant ions inhibit crystal growth and sintering between grains during heat treatment.

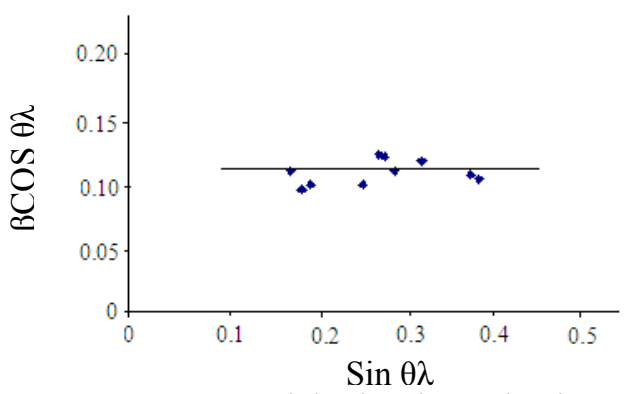

Figure 5. Particle size determination.

The morphology and size of the synthesized $\mathrm{PbO}$ samples were investigated using scanning electron microscopy (SEM). SEM microstructures of samples have been presented in Figure 6(a-c). The surface of the catalyst presents a spongy discrete particle appearance. The elemental analysis (EDAX) indicates that calcined $\mathrm{PbO}$ nanoparticles contain $100 \%$ $\mathrm{PbO}$. The $\mathrm{Ni}$ doped $\mathrm{PbO}$ nanoparticles contains 3\% $\mathrm{Ni}$ and $7 \% \mathrm{Ni}$ ion (Figure $6 \mathrm{~b} \& \mathrm{c}$ ). Thermogravimetric analysis (TGA) shows that there is no considerable loss in weight. TGA curve proves the existence of lead oxide which does not decompose up to $580{ }^{\circ} \mathrm{C}$ (Figure 7). The ESR spectrum shows that the $\mathrm{PbO}$ and $\mathrm{Ni}$ doped $\mathrm{PbO}$ semiconducting nanoparticles consists of unpaired electron. From ESR signal the effective $g$ value for unpaired electron was observed to be 2.00277 , which gives a clear evidence of paramagnetism in the $\mathrm{PbO}$ nanomaterial (Figure 8). 

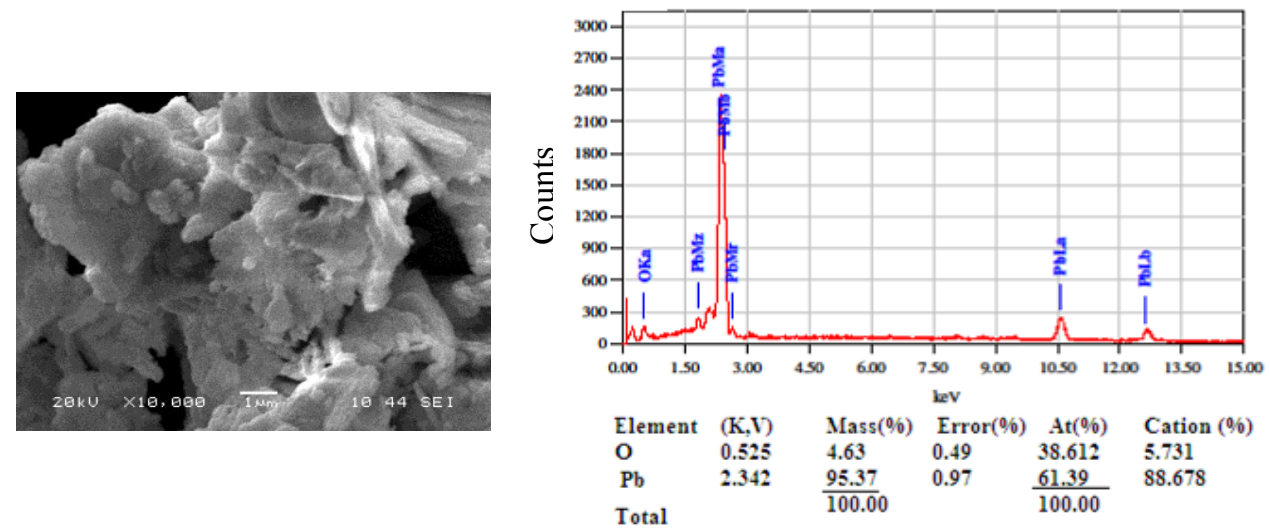

Figure 6 a)
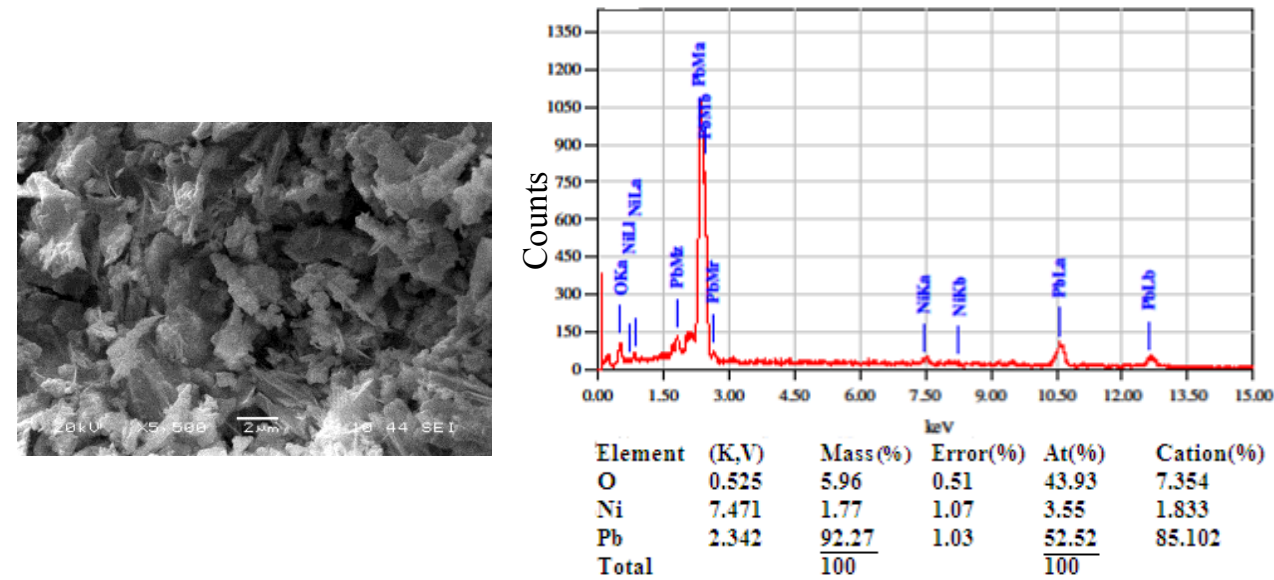

Figure 6 b)

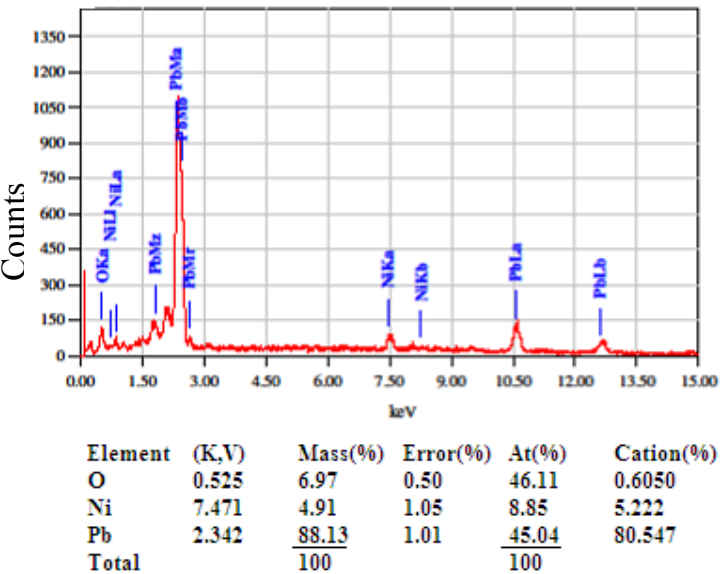

Figure 6 c)

Figure 6. SEM images and EDAX of a) $\mathrm{PbO}$ nanoparticle, b) $3 \% \mathrm{Ni}$ doped $\mathrm{PbO}$ nanoparticle, c) $7 \% \mathrm{Ni}$ doped $\mathrm{PbO}$ nanoparticle. 


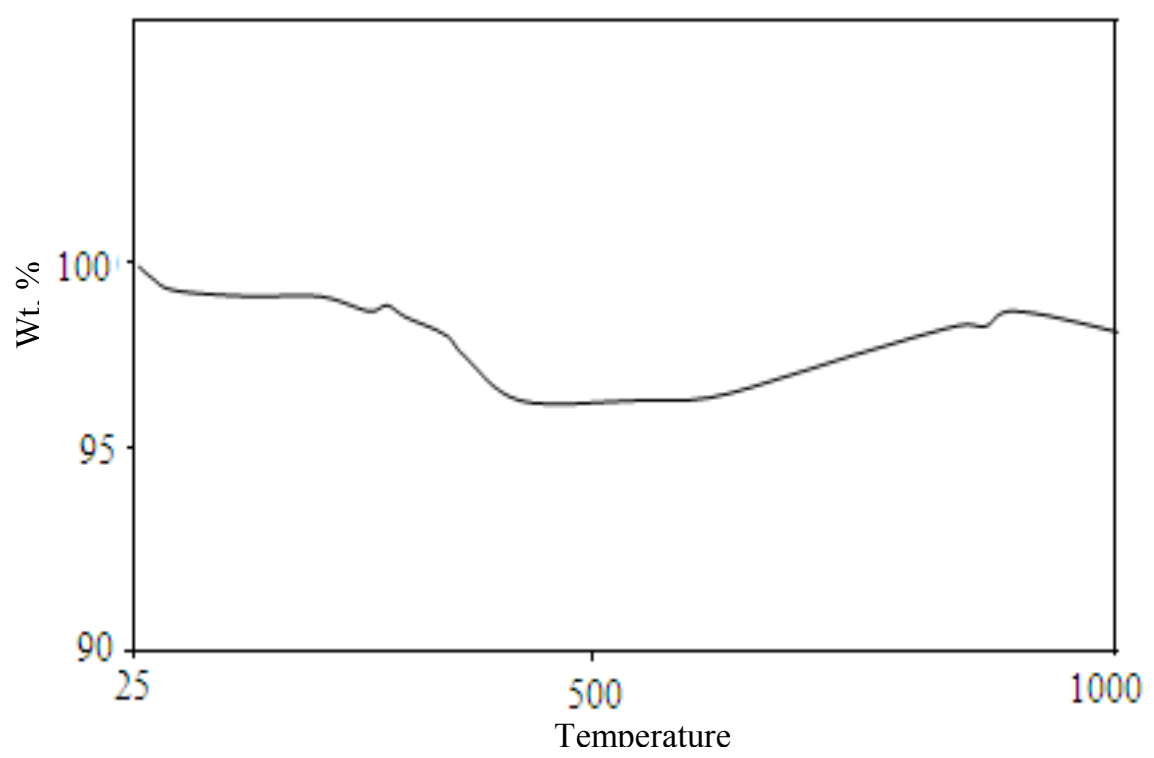

Figure 7. TGA spectrum of $\mathrm{PbO}$ nanoparticle.

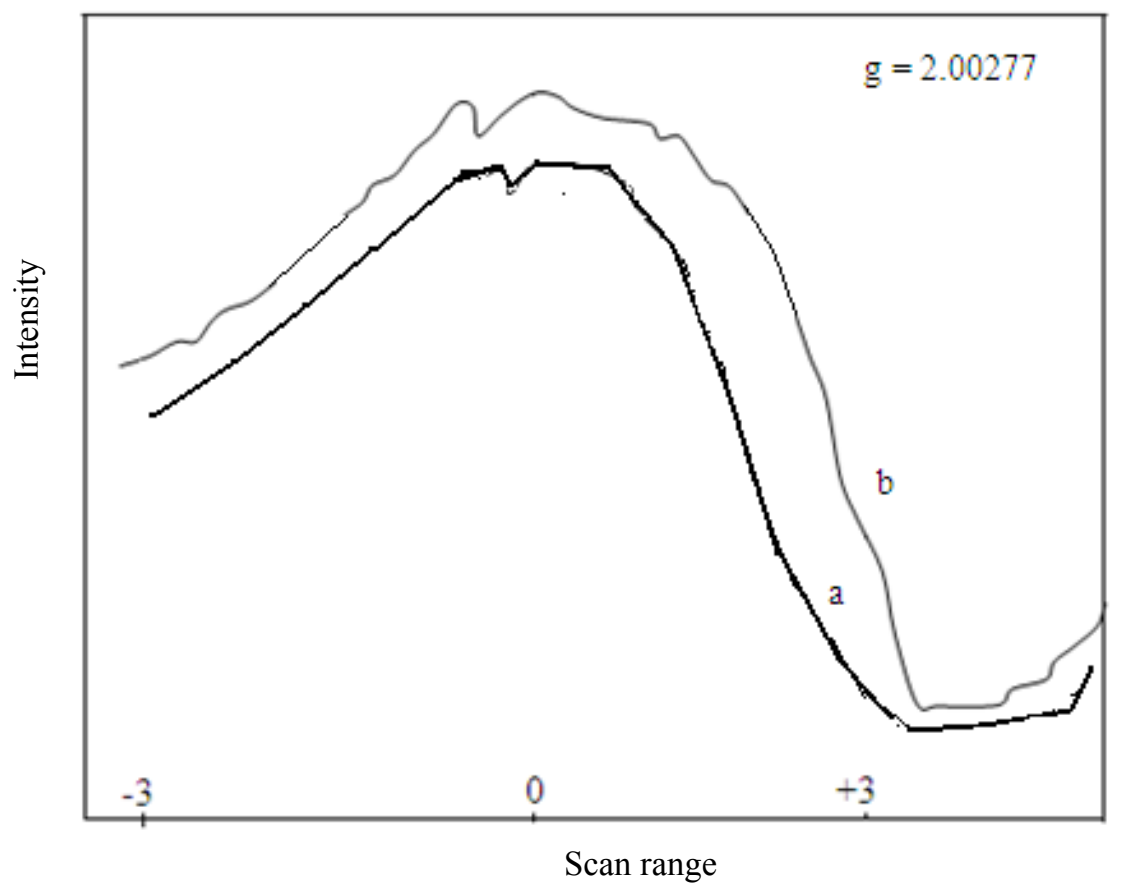

Figure 8. ESR spectrum a) $\mathrm{PbO}$ nanoparticle, b) 3\% Ni doped $\mathrm{PbO}$ nanoparticle.

\section{Photodegradation studies of $M B$}

Photodegradation process assisted by semiconducting $\mathrm{PbO}$ nanoparticles depends on various parameters like nature and concentration of organic substance, concentration and 
type of the semiconductor photocatalyst, light source and intensity, $\mathrm{pH}$ and temperature. ${ }^{27}$ Earlier report shows that, the photocatalytic degradation of dyes follows first-order kinetics. ${ }^{28,29}$. The present investigation also reveals that $\mathrm{PbO}$ nanoparticles induced photocatalysis of $\mathrm{MB}$ follows pseudo-first order kinetics with respect to $\mathrm{MB}$ concentration (Table 1). The rate constant (Figure 9a) for this reaction is obtained by using the expression $\mathrm{K}=-2.303 \times$ Slope is found to be $\mathrm{K}=3.015 \times 10^{-4} \mathrm{sec}^{-1}$ (Table $1 \& 2$ ).

Table 1. A Typical Run- Dye $=1.5 \times 10^{-4} \mathrm{M} / \mathrm{L}$, Photocatalyst $=50 \mathrm{mg}$.

\begin{tabular}{ccc}
\hline Time, $\min$ & O.D & $2+\log$ O.D \\
\hline 00 & 1.071 & 2.000 \\
30 & 0.663 & 0.821 \\
60 & 0.540 & 1.732 \\
90 & 0.330 & 1.518 \\
120 & 0.170 & 1.230 \\
150 & 0.072 & 0.857 \\
180 & 0.025 & 0.397 \\
\hline
\end{tabular}

Table 2. Effect of $\mathrm{pH}$ on rate constant.

\begin{tabular}{cc}
\hline $\mathrm{pH}$ & $\mathrm{K}\left(\mathrm{sec}^{-1}\right) \times 10^{-4}$ \\
\hline 2.0 & 1.322 \\
4.0 & 1.509 \\
6.0 & 3.326 \\
8.0 & 6.930 \\
10.0 & 0.146 \\
12.0 & 4.107 \\
\hline
\end{tabular}

\section{Effect of initial dye concentration}

The effect of $\mathrm{MB}$ concentration on degradation was studied by varying the concentration from $1 \times 10^{-4} \mathrm{M}$ to $7 \times 10^{-4} \mathrm{M}$ and keeping $\mathrm{PbO}(50 \mathrm{mg} / 50 \mathrm{~mL})$ as constant. The degradation of MB was found to be decrease at high initial dye concentration (Figure 9b). The active surface on the catalyst available for reaction is very crucial for the degradation. At constant amount of catalyst when dye concentration increases, very few active sites of photocatalyst are available for reaction. At high concentration of dye, solution becomes more intense coloured and path length of photons entering the solution decreased. As an effect of this only few photons reached to the catalyst surface. Due to this the production of hydroxyl radical and superoxide radicals are limited and photodegradation was found to be negligible.

\section{Effect of $p H$}

The $\mathrm{pH}$ of the dye solution was adjusted using varying concentration of $\mathrm{HCl}$ and $\mathrm{NaOH}$. The maximum degradation of dye was recorded at the $\mathrm{pH} 10$ (Figure 9c). The $\mathrm{pH}$ affects not only the surface properties of $\mathrm{PbO}$ photocatalyst but also the dissociation of dye molecules and the formation of hydroxyl radicals. At alkaline conditions more hydroxyl radicals were formed and hence enhance the rapid degradation of dye solution. 


\section{Effect of amount of $\mathrm{PbO}$ photocatalyst}

Photodegradation of $\mathrm{MB}$ dye was carried out by taking different amounts of $\mathrm{PbO}$ and keeping dye concentration constant at $3 \times 10^{-4} \mathrm{M}$ (Figure 9d). It was found that the rate of degradation increases up to $75 \mathrm{mg} / 50 \mathrm{~mL}$ of the $\mathrm{PbO}$ photocatalyst, beyond which it shows a drastic reduction. The increase in degradation activities of MB dye with $\mathrm{PbO}$ photocatalyst amount may be due to an increase in the active sites available on the catalyst surface for the reaction, which in turn increases the rate of radical formation. The reduction in the degradation of dye, when the catalyst amount is increased beyond $75 \mathrm{mg} / 50 \mathrm{~mL}$ is due to light scattering and the reduction in light penetration through the solution. With a higher amount the deactivation of activated molecules by collision with ground state molecules dominates the reaction.
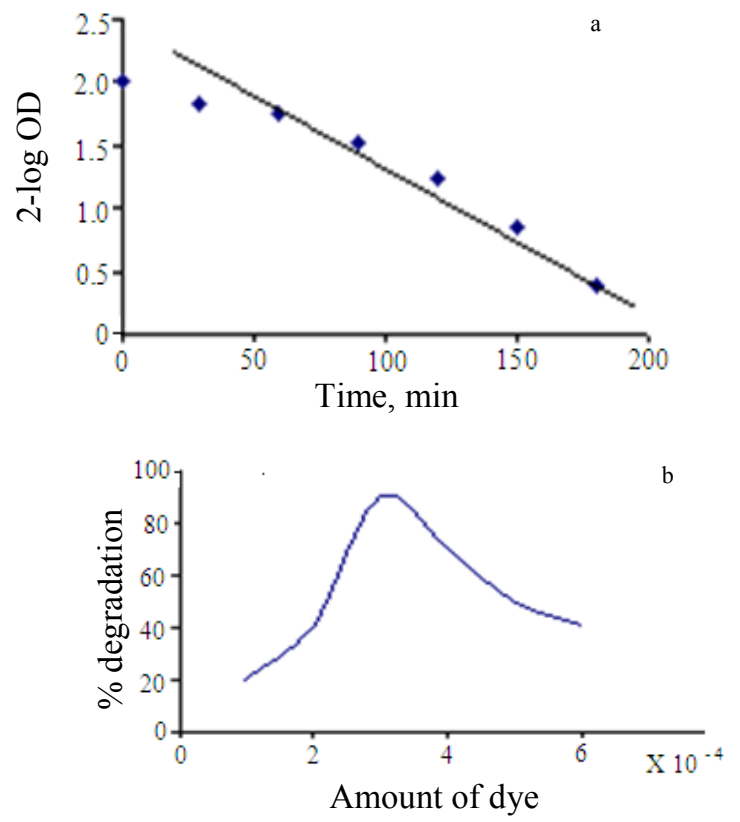
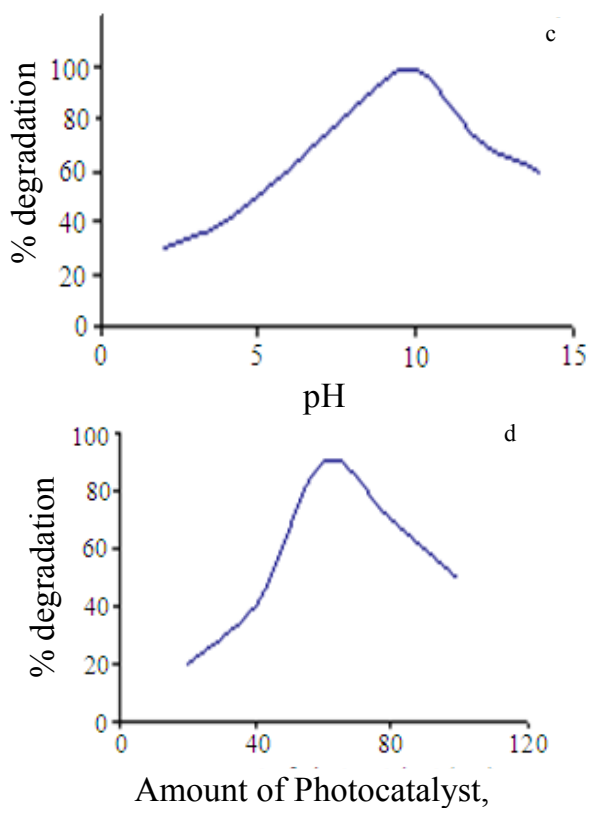

Figure 9. a) Rate constant of dye degradation, b) Effect of amount of dye on dye degradation, c) Effect of $\mathrm{pH}$ on dye degradation, d) Effect of amount of photocatalyst on dye degradation.

\section{Effect of nature of $\mathrm{PbO}$ photocatalyst}

Experiments were carried out with different photocatalyst such as $\mathrm{PbO}, 3 \%$ and $7 \% \mathrm{Ni}$ doped $\mathrm{PbO}$ and keeping $\mathrm{MB}$ dye concentration $3 \times 10^{-4} \mathrm{M}$ (Figure 10). It was found that degradation of $\mathrm{MB}$ was more with $3 \%$ and $7 \% \mathrm{Ni}$ doped $\mathrm{PbO}$ than $\mathrm{PbO}$ photocatalyst. The presence of $\mathrm{Ni}$ ion in $\mathrm{PbO}$ photocatalyst shifts the absorption of light towards visible range. The band gap energies for $3 \% \mathrm{Ni}$ and $7 \% \mathrm{Ni}$ doped $\mathrm{PbO}$ photocatalyst was minimum as compared to band gap energy of $\mathrm{PbO}$ photocatalyst. Due to this $\mathrm{Ni}$ doped $\mathrm{PbO}$ are more effective as compared to $\mathrm{PbO}$ photocatalyst. 


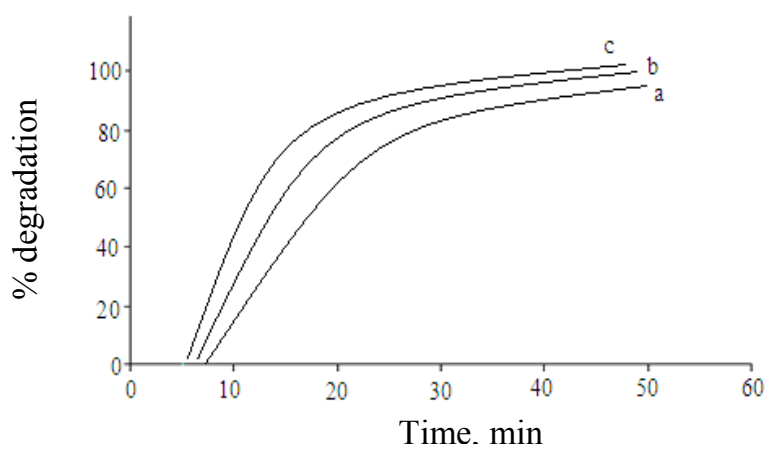

Figure 10. Effect of nature of photocatalyst, a) $\mathrm{PbO}$ photocatalyst, b) $3 \% \mathrm{Ni}$ doped $\mathrm{PbO}$ photocatalyst, c) $7 \% \mathrm{Ni}$ doped $\mathrm{PbO}$ photocatalyst.

\section{Efficiency of reused $\mathrm{PbO}$ photocatalyst}

The $\mathrm{PbO}$ nanoparticle photocatalyst used in the photocatalytic reaction was dried at $40-50{ }^{\circ} \mathrm{C}$ in a hot air oven before it was reused as such in the succeeding photocatalytic experiment. The photodegradation efficiency of $\mathrm{PbO}$ photocatalyst shows a smaller change after repetitive use. It indicates the cost effectiveness of this method.

\section{Estimation of chemical oxygen demand (COD)}

The chemical oxygen demand (COD) was widely used to measure the organic strength of waste water. The COD of the dye solution was estimated before and after the treatment. The reduction in the COD values of the treated dye solution indicates the mineralization of the dye molecules. The degradation efficiency is calculated from following equation. The results obtained are reported in Table 3. In the present work maximum $91.11 \%$ degradation efficiency was obtained.

$$
\text { Photodegradation efficiency }=\frac{\text { Initial }_{\mathrm{COD}}-\text { Final }_{\mathrm{COD}}}{\text { Initial }_{\mathrm{COD}}} \times 100
$$

Table 3. Chemical Oxygen Demand (COD) in methyl blue dye.

\begin{tabular}{cccc}
\hline $\begin{array}{c}\text { Dye Solution, } \\
\mathrm{M} / \mathrm{L}\end{array}$ & $\begin{array}{c}\text { Initial COD, } \\
\mathrm{mg} / \mathrm{L}\end{array}$ & $\begin{array}{c}\text { Final COD, } \\
\mathrm{mg} / \mathrm{L}\end{array}$ & $\begin{array}{c}\text { Photodegradation } \\
\text { efficiency, } \%\end{array}$ \\
\hline $1 \times 10^{-4}$ & 26.4 & 8.0 & 69.69 \\
$2 \times 10^{-4}$ & 40.0 & 10.4 & 74.00 \\
$3 \times 10^{-4}$ & 73.6 & 17.6 & 76.08 \\
$4 \times 10^{-4}$ & 128.0 & 18.4 & 85.62 \\
$5 \times 10^{-4}$ & 216.0 & 19.2 & 91.11 \\
\hline
\end{tabular}

\section{Conclusion}

$\mathrm{PbO}, 3 \%$ and $7 \%$ Ni doped $\mathrm{PbO}$ semiconducting nanoparticles was successfully synthesized by hydrothermal method. The $\mathrm{PbO}$ nanoparticles have orthorhombic structure with particle size $69 \mathrm{~nm}$. The 3\% Ni and 7\% Ni doped $\mathrm{PbO}$ have particle size 64 and $61 \mathrm{~nm}$ respectively. Encapsulation of nickel ion in $\mathrm{PbO}$ decreases the particle size which enhances the photocatalytic activity of $\mathrm{PbO}$ photocatalyst. The $\mathrm{PbO}$ and $\mathrm{Ni}$ doped $\mathrm{PbO}$ semiconducting nanoparticles exhibit significant photocatalytic activity for the organic dye. The degradation of dye catalyzed by $\mathrm{PbO}$ and $\mathrm{Ni}$ doped $\mathrm{PbO}$ semiconducting nanoparticles under visible light 
followed a radical type mechanism. The result shows the reduction in the chemical oxygen demand (COD) for dye along with colour removal using $\mathrm{PbO}$ nanoparticles.

\section{Acknowledgment}

Authors are thankful to Principal, HPT Arts and RYK Science College Nasik and Principal, P.V.P College Pravaranagar, for providing necessary laboratory facilities and Department of Physics, Pune University for providing characterization facilities.

\section{References}

1. Daheshwar N, Salari D and Khataee A R, J Photochem.and Photobio.A: Chem., 2003, 157(1)A, 111.

2. Wang J, Ma T, Zhang G, Zhang Z, Zhang X, Jiang Y, Zhao G and Zhang P, $J$ Cat Comm., 2007, 18 (1), 607.

3. Cheng P, Deng C, Gu M and Shangguan W, J Mater Sci., 2007, 42, 9239.

4. Ameta R, Vardia J, Punjabi P B and Ameta S C, Ind J Chem Tech., 2006, 13, 114.

5. Nagaveni K, Sivalingam G, Hegde M S and Madras G, J Appl Catat B, 2004, 48, 83.

6. Asahi R, Morikawa T, Ohwaki T, Aoki K and Taga Y, Science, 2001, 293, 269.

7. Ji H, Ma W, Huang Y, Zhao J and Wang Z, J Chin Sci Bull., 2003, 48, 2199.

8. Zhao W, Chen C, Li X and Zhao J, J Phys Chem B, 2002, 106 (19), 5022.

9. Nigam P, Armour G Banat I M, Singh D and Marchant R, J Bioresour Technol., 2000, 72, 219.

10. Khan T A, Singh V V and Kumar D, J Sci Ind Res., 2004, 63, 355.

11. Ramuthai S, Nandakumar V, Thirucheli M, Avivoli S and Vijayakumaran V, E-J Chem., 2009, 6 (S1), S 363.

12. Karthikeyan S, Sivakumar B and Sivakumar N, E-J Chem., 2010, 7 (S1), S175.

13. Baskaran P K, Venkatraman B R and Avivoli S, E-J Chem., 2011, 8 (1), 9.

14. Thakare S R and Bhave N S, E-J Chem., 2005, 2(1), 62.

15. Konstantinov K, Ng S H, Wang J Z, Wang G X, Wexler D and Liu H K, J Power Sources, 2006, 159 (1), 241.

16. Li S,Yang W, Chen M, Gao J, J. Kang J and Qi Y, J Mater Chem And Phy., 2005, 90 (2-3), 262.

17. Wang J, Zhong S, Konstantinov K, Ahn J H, Liu H K and Dou S X, J Meta Nanocryst Mater., 2007, 15-16, 367.

18. Shah M A, J Biomed Nanosci Nanotech., 2006, 1(1), 3.

19. Souther R H and Alspaugh T A, J Water Pollution Control Federation, 1957, 29, 804.

20. Jia B and Gao L, J Mater Chem Phys., 2006, 100 (2-3), 351.

21. Raju V, Murthy S, Gao F, Lu Q and Komarneni S, J Mater Sci., 2006, 41(5), 1475.

22. Chen S and Li N, J Mater Chem., 2002, 12, 1124.

23. Zhou Q, Liu X Y, Liu L, Li Y G, Jiang Z Y and Zhao D Y, J Chem Lett., 2005, 34 (9), 1226.

24. Juan C L, Mao Z.S, Shen W Z, Jun Z.Z and Xin D H, J Mater Lett., 2005, 59(24-25), 3119.

25. Jiang X, Wang Y, Herricks T and Xia Y, J Mater Chem., 2004, 14 (4), 695.

26. Hsieh C T, Chen J M, Lin H H and Shih H C, J Appl Phys Lett., 2003, 83, 3383.

27. Ferraz A M C, Maser S and Jonhaeuser M J, Fuel., 1999, 1567.

28. Panduranga A, Kamal S, Uma S, Palanichamy M and Murugesan V, Ind $J$ Chem Technol.,.2001,8, 496.

29. Lachheb H, Puzenat E, Houas A, Ksibi M, Elaloui E, Guillard C and Herrmann J M, $J$ Appl Catal B Environ., 2002, 39, 75. 


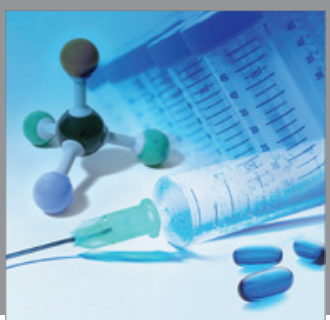

International Journal of

Medicinal Chemistry

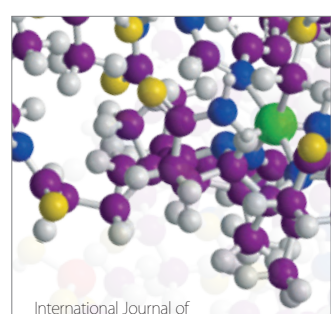

Carbohydrate Chemistry

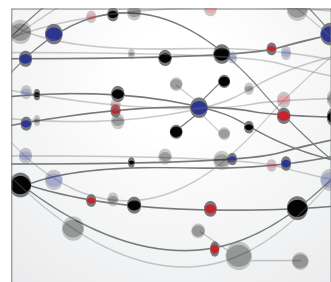

The Scientific World Journal
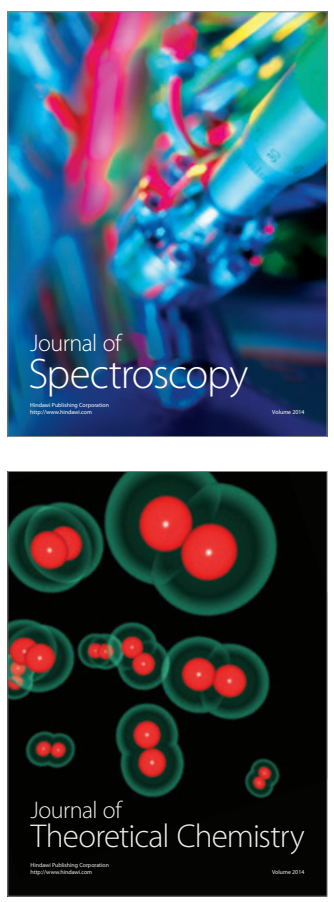
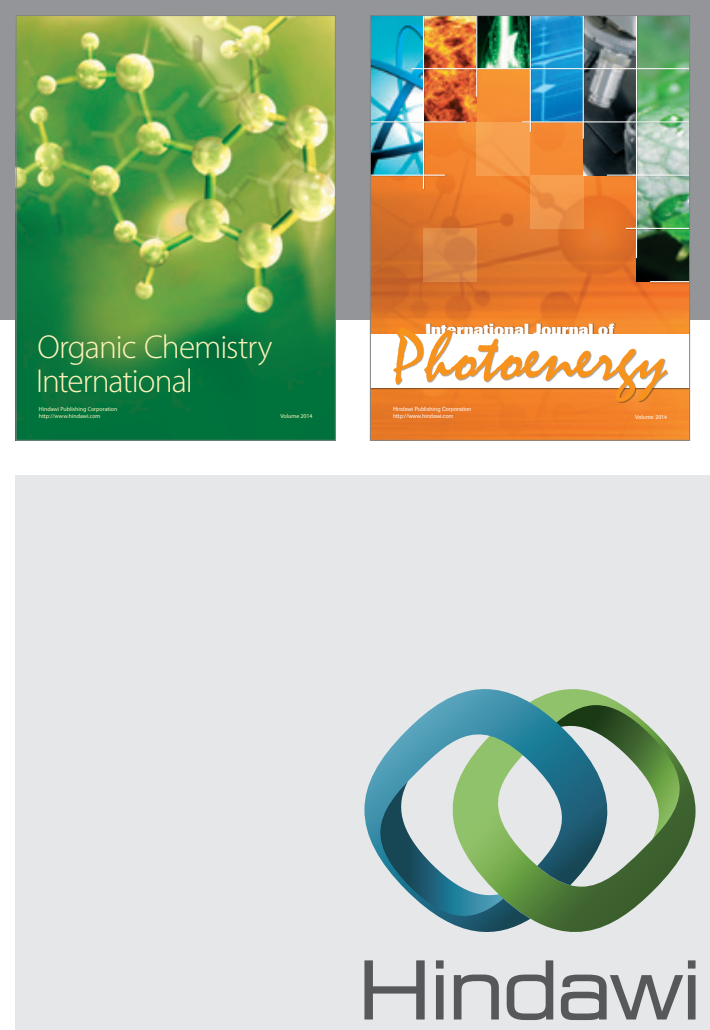

Submit your manuscripts at

http://www.hindawi.com
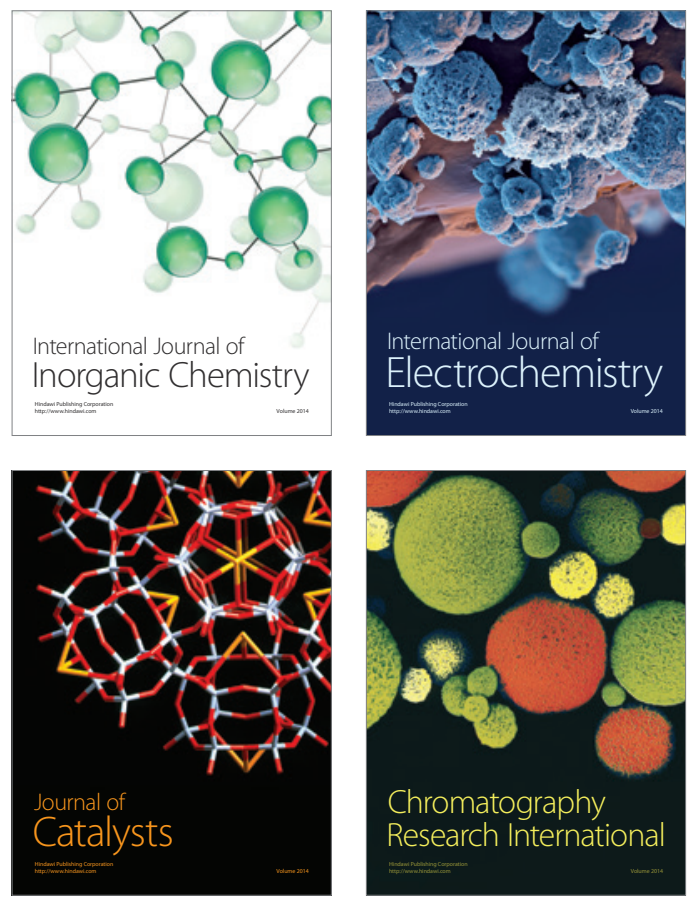
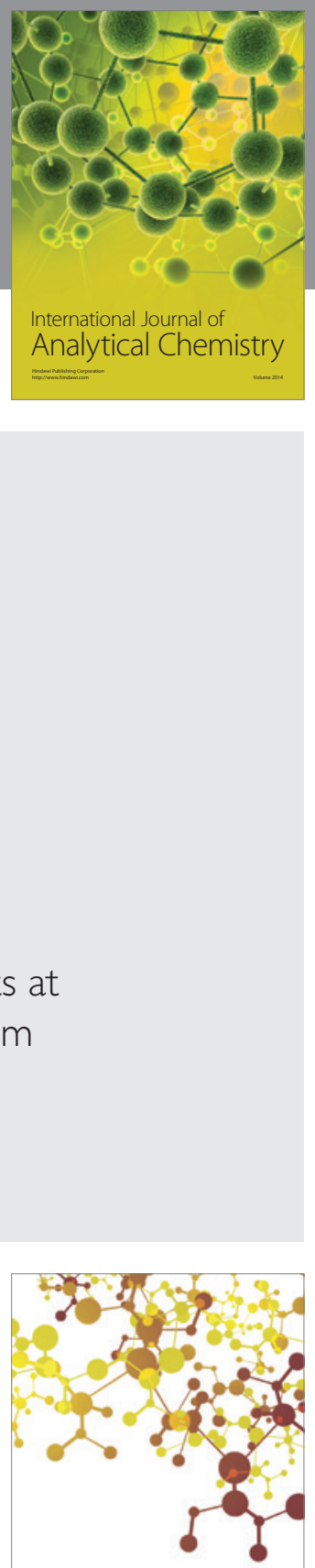

Journal of

Applied Chemistry
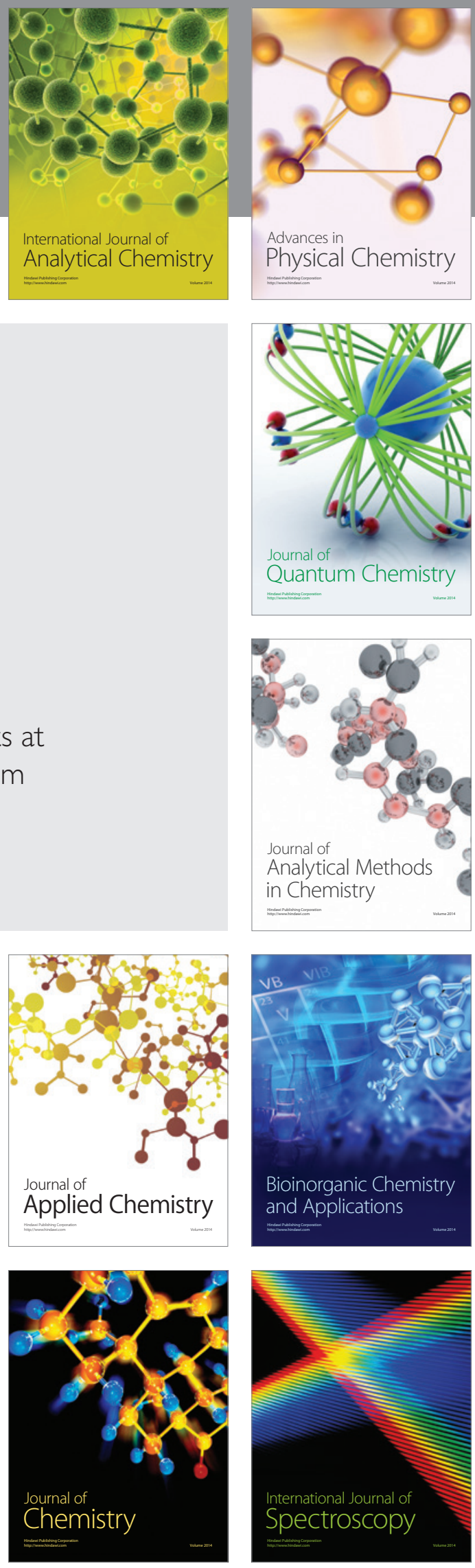